Conservative therapy in patients with hypertrophy o lymphadenoid pharynx tissue including both the traditional and antioxydant therapy with the use of different kinds of low intensive lases promoted the elimination of this pathology in $89,2 \%$ of cases of patients.

Thus, children suffering from severe form of snore phenomenon and SOSA belongs to the risk group according to the syndrome of sudden death.

Questionary conducted enabled to reveal a group of such patients and direct them for the specialized treatment during which predisposed factors contributing to the development of the given pathology had been eliminated.

Literature:

1. Blotskiy A.A. Surgery treatment phenomenon of snoring and obstructive sleep apnea // Sovremene technology технологии.- 2001.-№ 3.-С. 38 - 42.

2. Blotskiy A.A., Pluzhnikov M.S. Phenomenon of snoring and obstructive sleep apnea. -SPb.:Spec. Lit., 2002. -176 c.

3. Blotskiy A.A., Pluzhnikov M.S. Primenenie Nd:YAG - laser of treatment phenomenon of snoring and obstructive sleep apnea //Folia otorhinolaryngologiae et Pathologiae Respiratoriae. - 2002. - Vol. 7. - № 1-2 . -C. 35-40.

4. Blotskiy A.A., Pluzhnikov M.S. Clinical analyses phenomenon of snoring and obstructive sleep apnea laser uvulopalathoplasty // Rossiskaiy rinolodgy. - 2002. - № 3. -C. 27-35.

5. Blotskiy A.A.., Deniskin O.N. Magnetic-resonance tomography diagnostic anatomical orofaryngial of the phenomenon of snoring and obstructive sleep apnea // Folia otorhinolaryngologiae et Pathologiae Respiratoriae. - 2004. - Vol. 10. - № 3-4. -C. 33-37.

6. Blotskiy A.A.., Rubis I.A. Epidemiology phenomenon of snoring and obstructive sleep apnea at children of the treatment chronic diseases of nasopharyngel organs // Folia otorhinolaryngologiae et Pathologiae Respiratoriae. - 2005. - Vol. 11. - № 1-2. - C.21-24.

7. Blotskiy A.A.., Rubis I.A. Antioxydant therapy diseases chronic tonsillitis at children of phenomenon of snoring and obstructive sleep apnea // Materials regions conference otorinolaryngology "Actual questions otorinolarungology». Blagoveshchensk. - 2006. -C. 66-69.

8. Blotskiy A.A., Pluzhnikov M.S. obstructive sleep apnea // Vestnik otorinolaringplogii. - 2008. - №4. -C.78-80.

9. Pluzhnikov M.S., Blotskiy A.A. Epidemiology phenomenon chronic diseases of nasopharyngel organs of snoring and obstructive sleep apnea of the leaser treatment // Vestnik otorinolaringplogii..-2002.-№3.-C. 12-15.

UDC 616.151.5-08-039.72 DOI 10.22448/AMJ.2017.3.111-113

\title{
ANALYSIS OF THE EFFICIENCY OF DABIGATRAN AND RIVAROXABAN PREPARATIONS WITH HEREDITARY HEMATOGE- NOUS THROMBOPHILIA
}

\author{
V.V. Voitsekhovsky, Yu.V. Suslova
}

\section{Amur State Medical Academy, Russia, Blagoveshchensk}

Summary The analysis of the cases of clinical manifestation and the effectiveness of secondary antithrombotic therapy in patients observed in the hematological office of the Amur regional polyclinic with the diagnosis of "hereditary hematogenic thrombophilia" was carried out. In most cases, the first manifestation of hereditary hematogenous thrombophilia is thromboembolism of the pulmonary artery $(60 \%)$. The young age of the patient, hereditary history of thrombosis, the absence of provoking factors for the development of thrombosis is the basis for examination for thrombophilia. Warfarin, long used as an antithrombotic therapy, has a large number of disadvantages. Drugs dabigatran and rivaroxaban are effective and safe preparations of secondary prevention of thrombosis and can be used in hereditary hematogenous thrombophilia. Absence of the need for constant laboratory monitoring and extremely rare hemorrhagic complications make it possible to use them in patients living in regions remote from large medical centers.

Keywords: hematogenous hereditary thrombophilia, thrombosis prevention

Under the term "hematogenous thrombophilia" Z.S. Barkagan understood all hereditary (genetically conditioned), and acquired (secondary, symptomatic) hemostasis disorders, which are prone to early onset and recurrence of thrombosis, thromboembolism, ischemia and infarction of organs [1]. WHO and the International Society for Thrombosis and Hemostasis (ISTH) in 1995 identified hereditary thrombophilia as an unusual incidence of thrombosis with an early age onset, a family history, a severity of thrombosis disproportionate to the known causative factor and episodes of recurrent thrombosis [11]. In 2008, the American College of Thoracic Doctors for antithrombotic and thrombolytic therapy defined thrombophilia as one or more of the following symptoms: deficiency of antithrombin, protein $\mathrm{C}$, protein $\mathrm{S}$, resistance to activated protein $\mathrm{C}$, mutation factor $\mathrm{V}$ Leiden, prothrombin mutation G20210A, hyperhomocysteinemia, homozygous carriage A thermolabile variant of methylenetetrahydrofolate reductase, antiphospholipid antibodies, an increase in the activity of factor VIII, or a decreased level of protein Z [6].

Hereditary hematogenous thrombophilia is characterized by: early manifestation, the absence of an obvious provocative factor and a single universal diagnos- 
Emergency treatment of acute thrombosis in patients with hematogenous thrombophilia is performed in accordance with accepted standards of treatment of this complication [3]. Secondary prophylaxis of thrombus formation since the beginning of the new century was mainly carried out with the use of warfarin. However, in the process of using this drug, a number of its shortcomings have been identified. First of all, this is the need for frequent laboratory monitoring in connection with a high risk of bleeding. In view of the peculiarities of the Russian Federation - low population density in large areas, considerable distance from a number of settlements from medical centers, etc., in many regions there is no possibility not only to control the INR, but also to observe the patient systematically. Other, less common complications of warfarin therapy are diarrhea, an increase in hepatic transaminase activity, osteoporosis, eczema, skin necrosis, vasculitis, and alopecia [2, 4]. Warfarin is contraindicated in the deficit of physiological anticoagulants - proteins $C$ and $S$. Some of the patients have a genetically determined high resistance to coumarins $[1,2]$.

Therefore, recently alternative drugs have been actively used to prevent thrombosis in patients who are for some reason contraindicated in warfarin. The most effective and convenient to use are oral anticoagulants - direct inhibitor of thrombin dabigatran [7], and direct inhibitors of factor $X$ - riwaroxaban [8] and apixaban [9]. Warfarin, at present, is the drug of choice only in patients with artificial heart valves [10].

Materials and methods of research The analysis of the cases of clinical manifestation and the effectiveness of secondary antithrombotic therapy in patients observed in the hematological office of the Amur regional polyclinic with the diagnosis of "hereditary hematogenic thrombophilia" was carried out. In the formulation of this diagnosis, the approach was used according to which only the registered fact of thrombosis, thromboembolism, ischemia or infarction of the organs is the basis for the diagnosis of "hematogenous thrombophilia" and further prevention of thrombus formation; carrying of genetic factors of increased blood clotting, without clinical manifestations and changes in the coagulogram is designated by the term - "factors of thrombogenic risk", the presence of hypercoagulation or activation of platelets determined by laboratory methods, but without the recorded facts of thrombotic complications - by the term "state of thrombotic readiness" [5] . Outpatient cards of 65 patients with the diagnosis of "hereditary hematogenous thrombophilia" were studied.

The results of the study and their discussion In 39 patients from this cohort (60\%), the disease debuted with pulmonary embolism (PE), without any external causes for the development of this complication. In two cases (1.3\%), myocardial infarction occurred in the onset of the disease, in 8 cases $(12.3 \%)$ - ischemic stroke, in $16(26.4 \%)$ - the pathology of the veins of the lower extremities. But with a full examination, the pathology of deep or superficial veins of lower extremities of different degrees was diagnosed in 45 patients with hereditary hematogenous thrombophilia. By the time these patients were referred to the hematologist, and the diagnosis was verified, the majority of the history had already had multiple vascular complications. It is concluded that PE is the first thrombogenic manifestation of the disease in more than half of these patients.

Basically, these were patients of a young age, their lack of apparent provoking factors for the development of thrombotic complications, burdened hereditary anamnesis, were the basis for conducting modern methods of studying the hemostasis system, including genetic ones. Age of patients at the time of diagnosis of "hematogenous thrombophilia": 17 - 20 years - three patients, 21 - 30 years - 23, 31 - 40 years - 24, 41-50 years - 10, 51-60 years - five patients.

In all cases, there was a combined form of hematogenous thrombophilia. In addition to several clinically significant genetic mutations and / or deficit of physiological anticoagulants, the acquired factors - hyperhomocysteinemia, and antiphospholipid syndrome - occurred. Among the clinically significant thrombogenic factors, mutations (in all cases, homozygotes) F5 Leiden were diagnosed in 32 patients (48\%), PAl-1 (inhibitor of plasminogen-1 activators) in 40 (62\%), prothrombin F2 G20210A in 25 (38\%); A deficiency of antithrombin III in 5 (7.6\%) and protein C in 12 (18\%); Hyperhomocysteinemia in 25 (38\%), antiphospholipid syndrome in 15 (24\%) patients.

Immediate therapy for thrombosis of various locations was carried out in accordance with accepted standards.

Dabigatran (pradax) drug, 35 patients with hereditary hematogenous thrombophilia aged 20 to 50 years were prescribed for the prevention of thrombosis. In the history of diagnosis: 21 patients - PE (in 14 cases relapsing), in 5 - ischemic stroke, in 2 - myocardial infarction, in 20 there was a pathology of the vessels of the lower extremities. The duration of dabigatran from six years, up to several months. The dose of the drug was individually selected from 150 to $300 \mathrm{mg}$ per day.

The drug rivaroxaban (xarelto), for the prevention of thrombosis, 20 patients with hereditary hematogenous thrombophilia aged 18 to 54 years were prescribed. In the history of diagnosis: 13 patients - PE (in 5 cases, recurrent), in 2 - ischemic stroke, in 15 cases there was a pathology of the vessels of the lower extremities. Duration of taking rivaroxaban from four years, up to several months. The dose of the drug is 10-20 mg per day.

In 15 patients, in addition to the above factors, platelet hyperaggregation was detected, dabigatran or rivaroxaban therapy was combined with acetylsalicylic acid preparations. With hyperhomocysteinemia, angiovitis or pentavit was prescribed. Preparations of protein C and antithrombin III for their congenital deficiency were used according to indications.

After the appointment of dabigatran or rivaroxaban, no patient recurred any life-threatening thrombotic complications. When dabigatran is used, hemorrhagic complications are not diagnosed. At the same time, 4 patients treated with rivaroxaban experienced nasal bleeding; in two cas- 
es they stopped with a dose reduction from 20 to $10 \mathrm{mg}$, two patients were transferred to dabigatran.

At the same time, 25 patients lived in remote areas and could not regularly monitor the coagulogram.

Only 10 patients with a diagnosis of "hereditary hematogenous thrombophilia" are currently taking warfarin. These are patients who have long been using this drug, which control the coagulogram indicators (primarily INR) and refuse to switch to new oral anticoagulants for the above reasons or for financial reasons. Five of them had a history of PE (in 2 cases recurrent), one patient had an ischemic stroke, and all had a lower extremity vessel pathology.

Conclusions

1. In most cases, the first manifestation of hereditary hematogenous thrombophilia is PE. According to our data - in $60 \%$ of cases.

2. In all cases, a combined form of hematogenous thrombophilia is diagnosed. Among the clinically significant thrombogenic factors, the predominant mutation was PAI-1, 62\%, with less frequent mutations F5 Leiden $48 \%$, prothrombin F2 G20210A 38\% (in all cases homozygotes), antithrombin III deficiency $7.6 \%$ and protein C 18\% . In addition to hereditary, in a number of cases there were acquired thrombogenic factors - hyperhomocysteinemia (38\%), and antiphospholipid syndrome (24\%).

3. The patient's young age, hereditary history of pathological thrombosis, absence of provoking factors for thrombosis is the basis for suspicion and a complete examination for hematogenous thrombophilia.

4. Preparations of dabigatran and rivaroxaban are an effective means of preventing thrombosis in such patients. Timely diagnosis of the disease and the appointment of adequate antithrombotic therapy contributes to the disease-free course.

5. High efficiency, rare hemorrhagic complications of dabigatran and rivaroxaban allow using these drugs in patients living in regions remote from large medical centers.

\section{References}

1. Barkagan, Z.S. Prethrombotic conditions and thrombophilia // Guide to hematology / ed. Al Vorobyov. - M: Nyediamed, 2005. T3. - P. 133 - 147.

2. Belousov Yu.B., Kukes VG, Lepakhin VK, Petrova VI Clinical pharmacology. National leadership. - Moscow: GEOTAR-Media, 2009. - 965 p.

3. Bokarev IN, Popova LV, Kozlova T.V. Thrombosis and antithrombotic therapy in clinical practice. Moscow: MIA, $2009 .-511$ p.

4. VV Voitsekhovsky. The use of dabigatran for the prevention of thrombosis in patients with hematogenous thrombophilia // Amur Medical Journal. - 2014. - No. 1 (5). - P. 92-100.

5. Momot A.P. Modern methods of recognition of thrombotic state. - Barnaul: Publishing house of the Altai State University, 2011. - 138 p.

6. Bates S.M., Greer I., Pabinger I., Sofaer S., Hirsh J., American College of Chest Physicians. Venous Thromboembolism, Thrombophilia, Antithrombotic Therapy, and Pregnancy American College of Chest Physicians Evidence-Based Clinical Practice Guidelines (8th Edition) // Chest. - 2008. - V.133. - P. 844-886.

7. Eriksson B.I., Dahl O.E., Rosencher N., Kurth A.A., van Dijk C.N., Frostick S.P., Prins M.H., Hettiarachchi R., Hantel S., Schnee J., Büller H.R., RE-NOVATE Study Group. Dabigatran etexilate versus enoxaparin for prevention of venous thromboembolism after total hip replacement: a randomised, double-blind, non-inferiority trial // Lancet. - 2007. - №370. - P. 949-956.

8. Patel M.R., Mahaffey K.W., Garg J., Pan Guohua, Singer D.E., Werner H., Breithardt G., Halperin J.L., Hankey G.J., Piccini J.P., Becker R.C., Nessel C.C., Paolini J.F., Berkowitz S.D., Fox K.A.A., Califf R.M. and the ROCKET AF Steering Committee, for the ROCKET AF Investigators. Rivaroxaban versus warfarin in nonvalvular atrial fibrillation // N. Engl. J. Med. - 2011. - №365. - P. 883-891.

9. Raskob G.E., Gallus A.S., Pineo G.F., Chen D., Ramirez L-M., Wright R. T., Lassen M. R. Apixaban versus enoxaparin for thromboprophylaxis after hip or knee replacement: pooled analysis of major venous thromboembolism and bleeding in 8464 patients from the ADVANCE-2 and ADVANCE-3 trials // J. Bone Joint Surg. Br. - 2012. - №94. - P. 257-264.

10. Stephen H. McKellar, Stuart Abel, Christopher L. Camp, Rakesh M Suri, Mark H. Ereth, Hartzell V. Schaff. Effectiveness of dabigatran etexilate for thromboprophylaxis of mechanical heart valves // The Journal of Thoracic and Cardiovascular Surgery. 2011. - June, 141 (6). - P. 1410-1416.

11. World Health Organization: Inherited Thrombophilia: Report of a Joint WHO. International Society of Thrombosis and Haemostasis (ISTH) Meeting. - Geneva: World Health Organization, 1995. 